\title{
Comunicação no Ciberespaço: diálogos acerca de Matemática ${ }^{1}$
}

\author{
Communication in Cyberspace: dialogues about Mathematics
}

\author{
Rosa Monteiro Paulo \\ rosa@,feg.unesp.br
}

Miliam Juliana Alves Ferreira miliam arierref@,hotmail.com

\begin{abstract}
Resumo
Neste texto explicitamos compreensões acerca da comunicação que se dá no ciberespaço. Tal compreensão foi propiciada por uma pesquisa de mestrado desenvolvida pela segunda autora deste texto com orientação da primeira autora. Questionamos, na pesquisa, as possibilidades do ciberespaço como espaço comunicativo, acompanhando comunidades virtuais do Facebook e do Orkut que discutem Matemática. Focamos os modos de expressão dos participantes procurando esclarecer como a comunicação acerca da Matemática se dá no ciberespaço. A comunicação e expressão são tematizadas à luz das ideias de Merleau-Ponty e o ciberespaço é assumido como nas pesquisas de Bicudo e Rosa. A postura fenomenológica orienta os caminhos da pesquisa e a interpretação dos dados desvela, dentre outros aspectos, que o ciberespaço é aberto à comunicação e possibilita modos de expressão pela fala, por meio de imagem e pela linguagem matemática. A expressão pela fala é discutida neste texto mostrando que o diálogo entre os sujeitos é possível quando se considera a abertura ao ouvir.
\end{abstract}

Palavras-chave: Educação Matemática; Fenomenologia; Pesquisa Qualitativa; Virtual.

\begin{abstract}
In this paper we introduce ourselves our understandings about the communication that takes place in cyberspace. Such understanding was caused by a master's research developed by the second author of this text orientation of the first author. In research interests us the possibilities of cyberspace as communicative space. For this follow two groups of social networks Facebook and Orkut discussing mathematics. The focus was the modes of expression of the participants to aiming to clarify how they talk about math in cyberspace. The communication and expression are themed based on studies of Merleau-Ponty and cyberspace is assumed to be in the research Bicudo and Rosa. The phenomenological approach guides the search paths and the interpretation of the data shows, among other things, that cyberspace is open to communication and enabling modes of expression by speech, by image and by mathematical language. The expression by speech is discussed in this paper showing that dialogue between subjects is possible when considering the opening to hear.
\end{abstract}

Keywords: Mathematics Education; Phenomenology; Qualitative Research; Virtual

\section{Introdução}

Este artigo tem por objetivo expor compreensões propiciadas por uma pesquisa de mestrado, orientada pela interrogação "como o diálogo acerca do conteúdo matemático é possível e se dá em comunidades e grupos das redes sociais Facebook e Orkut?”. Questionar

1 Este texto é fruto de análise das discussões ocorridas na apresentação de trabalho no VI Seminário Internacional de Pesquisa em Educação Matemática - SIPEM, realizado em novembro de 2015 em Pirenópolis, Goiás. A participação no evento foi possibilitada em virtude do apoio financeiro da Fundação de Amparo a Pesquisa do Estado de São Paulo-FAPESP. 
o como faz com que o pesquisador se volte para os modos pelos quais o investigado se dá. Assim, na pesquisa, voltamo-nos para os modos pelos quais os participantes de comunidades do Facebook e Orkut dialogam ou discutem Matemática. Para explicitar o sentido do que se interroga - e do obtido - trazemos, neste texto, aspectos da postura metodológica assumida - a fenomenologia - e da comunicação tal qual a entendemos em Merleau-Ponty (1994, 2002), o que permite explicitar o sentido de diálogo. O ciberespaço é o solo no qual as possibilidades de diálogo se abrem e o apresentamos trazendo as ideias de Bicudo e Rosa (2010). Feito isso, temos condições de expor o sentido da comunicação que se dá entre os participantes das redes sociais investigadas, cuja interlocução baseia-se em conteúdos matemáticos. Os procedimentos de análise de dados são fundamento para expor o que na pesquisa se desvelou e, por isso, compõem uma sessão deste texto. Finalizando o artigo trazemos considerações acerca da experiência vivida na pesquisa que nos permitem destacar particularidades do diálogo sobre Matemática nas redes sociais a partir da expressão pela fala.

\section{A postura fenomenológica: a rede que enlaça o fazer}

A postura assumida na pesquisa é a fenomenológica. Iniciando-se na Alemanha em fins do século XIX e na primeira metade do século XX, a fenomenologia teve como precursor, na linha do existencialismo, o filósofo e matemático Edmund Husserl (1859-1938). Husserl (2008) apresenta a fenomenologia como um método rigoroso de investigação que tem como propósito "ir ao encontro das coisas em si mesmas" (HUSSERL, 2008, p. 17). A intenção, na fenomenologia husserliana, é explicitar o sentido que as coisas do mundo faz para o sujeito. Para tanto, Husserl propõe a "análise compreensiva" da consciência, entendendo que todas as vivências (Erlebnis) do mundo se dão na e pela consciência. Segundo Fragata (1959, p. 130), para Husserl, "toda consciência é consciência de algo". A consciência "é como um ponto de convergência das operações humanas que nos permite dizer o que estamos dizendo ou fazer o que estamos fazendo como seres humanos" (ALES BELLO, 2006, p. 45). A consciência não é, nesse sentido, um lugar específico, seja ele físico ou psíquico. É antes, o movimento de voltar-se para o que se mostra abrangendo atos de intuição e percepção que possibilitam que o sujeito conheça, compreenda e expresse o compreendido. Esse modo de compreender da consciência, por sua vez, indica que a consciência não pode estar apartada da intencionalidade.

Para Husserl, "a palavra intencionalidade [do latim intentio] significa apenas a característica geral da consciência de ser consciência de alguma coisa" (FRAGATA, 1959, p. 130). A intencionalidade, na fenomenologia husserliana, é característica aos atos de 
conhecimento. Ou seja, para Husserl os atos sempre se referem a algo, sempre implicam em algum objeto de conhecimento, de tal modo que "pertence à essência das vivências de conhecimento (Erkentniserlebnisse) ter uma intentio, significar alguma coisa, referir-se a uma objetividade" (HUSSERL, 1950 apud COELHO JUNIOR, 2002, p. 97). Podemos interpretar que, para Husserl, o conhecimento implica uma consciência intencional voltada para algo. Essa é uma ideia importante na fenomenologia husserliana, que rompe com a dicotomia existente entre consciência e objeto. Compreendendo isso, se pode ver que não existe

uma consciência que constitua seus objetos, ou objetos que constituam uma
consciência, mas sim [há] uma intencionalidade, que é um movimento /.../ entre uma
consciência que só é se aberta para os objetos, e objetos que se mostram /.../
enquanto intencionais a essa consciência. (COELHO JUNIOR, 2002, p. 98).

Husserl propõe a análise dos fenômenos no âmbito da consciência, isto é, enquanto intencionais, de modo que o sujeito possa se voltar para as coisas em si mesmas buscando compreendê-las como elas são. Alguns estudiosos de Husserl, como por exemplo, Silva (s.d.), afirmam que o método fenomenológico de Husserl traz uma proposta para que o sujeito encare o mundo como se o fizesse pela primeira vez sem buscar explicá-lo, mas tentando deixá-lo se fazer ver.

Com isso, pode-se entender que a pesquisa que assume a postura fenomenológica permite que o pesquisador se volte para o que se mostra, deixando-o fazer-se ver. Isso exige do pesquisador rigor metodológico e um foco - ou uma interrogação - que lhe dirija o olhar sem que ele se deixe satisfazer por explicações causais ou teóricas. O pesquisador fenomenólogo deve deixar-se surpreender pelo que investiga sem, no entanto, perder-se nessa surpresa. É a surpresa do primeiro olhar, que vê com clareza algo que "salta aos olhos", que chama à atenção como se estivesse seduzindo o olhar. Esse "algo" que se mostra, que causa espanto e perplexidade, é o fenômeno que, para Bicudo (2011, p. 29), “diz do que se mostra na intuição ou percepção".

Entendendo o fenômeno como o que se mostra por si mesmo pode-se questionar como deve proceder o pesquisador fenomenólogo ao conduzir sua pesquisa?. Bicudo (2011) diz que ele deve estar atento ao que seus dados mostram e deve descrever isso que se mostra sem, nesse momento, buscar explicações ou justificativas. A descrição é importante na pesquisa fenomenológica, uma vez que, por meio dela, a compreensão do fenômeno torna-se possível. Vale destacar, porém, que a pesquisa fenomenológica não se limita à descrição. É preciso, além de descrever, explicitar o sentido disso que se mostra. É preciso interpretar e expor o compreendido. 
A pesquisa fenomenológica traz, portanto, a explicitação do compreendido e seu início é a interrogação que, ao longo da pesquisa, se mantém viva e motiva a compreensão. Essa compreensão não se esgota numa única possibilidade. Não se deixa aprisionar em uma explicação, uma vez que o percebido é orientado pelo sentido da interrogação, que abre possibilidades de compreensões diversas, exigindo rigor na interpretação.

$\mathrm{Na}$ pesquisa que originou este texto, a interrogação é: como o diálogo, acerca do conteúdo matemático, se dá em grupos das redes sociais Facebook e Orkut? Para ser possível explicitar os modos pelos quais o diálogo se dá entre os sujeitos da pesquisa, membros dessas redes sociais, foi preciso 'ir à coisa mesma'. Ou seja, como pesquisadores, acompanhamos grupos do Facebook e do Orkut focando os modos de expressão dos participantes. Esses modos de expressão, ou as formas encontradas pelos sujeitos para discutir conteúdos matemáticos nessas redes sociais, é o fenômeno interrogado. Ao acompanharmos esses grupos registramos as postagens dos sujeitos que foram se constituindo em dados da pesquisa. Descrevemos o que foi registrado e, seguindo os procedimentos da pesquisa fenomenológica, iniciamos a análise dos dados. No entanto, antes de adentrar a análise, consideramos significativo, para este texto, expor o sentido de comunicação e expressão para que o fenômeno expressivo no ciberespaço se mostre com clareza em nosso discurso.

\section{Comunicação e expressão: janelas que se abrem ao sentido}

Em Fenomenologia da Percepção (1994) e A Prosa do Mundo (2002), de MerleauPonty, abrem-se possibilidades de compreensão do sentido de comunicação e expressão na perspectiva fenomenológica. Maurice Merleau-Ponty (1908-1961) foi um filósofo e fenomenólogo francês que, seguindo a tradição fenomenológica de Edmund Husserl, desenvolveu seus estudos com ênfase no ser-no-mundo, buscando a experiência no mundovida e a expressão do sujeito pelo corpo próprio. O mundo é, para Merleau-Ponty, mundo percebido e em suas obras pode ser entendido como fenômeno, cujo sentido dá-se no momento da percepção, pela consciência doadora de sentido. O mundo se revela para o sujeito que se dirige ao mundo. O percebido é compreendido, interpretado e expresso. A expressão abarca inúmeras possibilidades desde o gesto até a palavra. A palavra, para Merleau-Ponty, carrega um sentido, veicula significação, de tal modo que é pela fala que o pensamento se realiza. Isso significa que há, "tanto naquele que escuta ou lê, como naquele que fala e escreve, um pensamento na fala" (MERLEAU-PONTY, 1994, p. 244). O pensamento e a expressão se constituem simultaneamente e, portanto, o pensamento não é “interior”, pois ele não existe fora do mundo e das palavras. Merleau-Ponty (1994, p. 193), 
diz que "o que nos faz crer num pensamento que existiria por si antes da expressão, são os pensamentos já constituídos e já exprimidos que podemos lembrar silenciosamente e pelos quais damos a ilusão de uma vida interior". Ainda, "um pensamento que se contentasse em existir para si, fora dos incômodos da fala e da comunicação, logo que aparecesse cairia na inconsciência, o que significa dizer que ele nem mesmo existiria para si" (MERLEAUPONTY, 1994, p. 241). Ou seja, se não for expresso o pensamento não se constitui. Assim, para Merleau-Ponty $(1994,249)$, "o pensamento e a expressão constituem-se simultaneamente /.../ e a fala é um verdadeiro gesto /.../ que torna possível a comunicação".

Essa possibilidade da comunicação existe porque vivemos em um mundo cuja fala já está instituída e, "o mundo linguístico e intersubjetivo não nos espanta mais, nós não o distinguimos mais do próprio mundo, e é no interior de um mundo já falado e falante que refletimos" (MERLEAU-PONTY, 1994, p. 250). Pode-se interpretar que Merleau-Ponty fala de uma familiariade que os sujeitos têm por compartilharem situações vividas em um mundo falante, que torna possível a comunicação. Ou seja, de acordo com Merleau-Ponty, o modo pelo qual nos expressamos faz sentido ao outro porque vivemos no mundo como cosujeitos. Isso não significa, porém, que temos uma mesma língua, mas temos a possibilidade de perceber e a possibilidade de expressar o percebido, fazendo-nos compreender. O sentido do percebido é comungado, compartilhado pelos sujeitos, que juntos vêem isso que faz sentido para ambos. A comunicação que expressa o percebido vai além da língua falada. Torna-se, como diz o autor, falante. Ou seja, eu me comunico com o outro por um gesto ou mesmo pelo silêncio. $\mathrm{O}$ outro que compartilha comigo uma experiência vivida é capaz de ler na minha fisionomia o gesto de tristeza, de alegria, de compreensão ou de desespero. É essa a comunicação de que nos fala Merleau-Ponty $(1994,2002)$ e que instala um sentido que é compartilhado no diálogo, nos modos de expressão.

O diálogo é, portanto, uma forma de comunicação que compartilha ideias e também é o que permite a formação de ideias sobre um determinado assunto uma vez que, pelo diálogo, o sujeito "sai da opinião particular" abrindo-se a generalidade, compartilhando, argumentando e tirando conclusões. Segundo o que expõe Merleau-Ponty (2002), pode-se compreender que, no diálogo, o falar do outro desperta em mim minhas próprias significações, assim como o meu falar - na forma de resposta, por exemplo - toca o outro, despertando-lhe para significações. O próprio silêncio está no diálogo, uma vez que, pelo silêncio, posso comunicar ao outro o meu desejo de não dizer ou mesmo uma discordância, indignação, dúvida, etc.

Entender o sentido do que Merleau-Ponty diz acerca da fala, do pensamento, do diálogo e da expressão, permite que olhemos para a comunicação que se dá no ciberespaço, buscando 
compreender como o "falar" de Matemática se expõe nos grupos das redes sociais Facebook e Orkut. Interessa-nos compreender os modos expressivos que permitem aos sujeitos, membros desses grupos, dialogar acerca de conteúdos matemáticos no ciberespaço.

\section{Ciberespaço: links que abrem possibilidades de compreensão}

Segundo Lévy (1999), o ciberespaço é definido como um espaço de comunicação aberto pela interconexão mundial de computadores e das memórias dos computadores.

É comum ouvir-se que a comunicação no ciberespaço ocorre de forma virtual. Mas, se a comunicação pressupõe um sentido que é comum, o que é o virtual? Bicudo e Rosa (2010), afirmam que o virtual tem suas raízes etimológicas no virtualis, cujo significado diz de força corporal, virtude, e do latim virtus, virtutis, que diz do possível, do potencial, do real. Afirmam que no âmbito do discurso filosófico, os significados de virtual apontam para o que existe como potência. Ou seja, a comunicação acontece como possibilidade que se atualiza mediante a intenção de dizer e de ouvir, usando os meios de comunicação disponíveis e considerando que as pessoas podem trocar informações das mais variadas formas, mediadas pelo aparato tecnológico.

Bicudo e Rosa (2010) também dizem que essa comunicação virtual (potencial) permite o diálogo entre sujeitos que compartilham de anseios e experiências comuns e se dispõem a dizer sobre o que compreendem. Por exemplo, se visamos a um computador, faz-se dele um objeto intencional e isso faz com que se dê a ele sentido, independente de perceber todas as suas qualidades ou conhecer todos os seus recursos. O computador, como objeto intencional para o qual nos voltamos, passa a integrar o mundo constituído pelo corpo que desenvolve um determinado esquema corporal em relação ao mundo (em que se tem o computador). Esse esquema corporal fica claro, por exemplo, quando consideramos a naturalidade com a qual falamos ao celular com o outro. Ou se consideramos o modo pelo qual os adolescentes interagem por meio da Internet. A partir de um dado momento o corpo já não percebe a máquina, tal sua familiaridade com ela; o objeto acaba tornando-se extensão do corpo, que percebe o mundo por ele. Mostra-se aqui o caráter do virtual, da potencialidade das tecnologias para a comunicação, por exemplo.

Bicudo e Rosa (2010) afirmam, ainda, que as tecnologias têm possibilitado um novo modo de comunicação e interação social e, além de potencializar a comunicação, o ciberespaço permite que as mensagens fiquem armazenadas e disponíveis para quem desejar retomá-las e reativá-las, isto é, voltar ao diálogo. Esse armazenamento possibilita, portanto, que o diálogo esteja 'sempre vivo' mesmo numa comunicação assíncrona (onde as mensagens 
não são instantâneas). Constitui-se, portanto, um ciclo no qual as intenções vão se expondo e formando uma teia de interesses e produção de significado expressa, que acontecem num certo tempo e podem ser retomadas e reavivadas a qualquer outro tempo e por qualquer outro sujeito.

É essa forma de expressão, que considera a intencionalidade como consciência, que nos apresenta objetos numa relação de significação original que traz o sentido primeiro do percebido. Essa forma de expressão é a que nos interessa na pesquisa, uma vez que procuramos entender como os usuários constroem pela Internet - nos grupos das redes sociais acima mencionados - o espaço expressivo de comunicação.

\section{Tecendo os fios da rede que expressa o interpretado}

Os dados da pesquisa constituíram-se mediante a um olhar do que era dito acerca de Matemática nas redes sociais. Buscamos por postagens dos sujeitos, relevantes para o que queríamos compreender, evitando repetições. Armazenamos os dados em um documento do Microsoft Word copiando e colando a postagem ou fazendo um print screen da tela. Nisso consistiu nossa coleta de dados da pesquisa.

Após esse procedimento nos dedicamos à análise dos dados. Para tanto, seguimos os quatro momentos diferentes que Fini (1994) descreve como sendo fundamentais na pesquisa de abordagem fenomenológica. Quais sejam: (1) leitura das descrições como um todo; (2) releitura das descrições identificando unidades de significado que permitam revelar aspectos do fenômeno investigado; (3) construção de asserções articuladas das unidades de significado e (4) busca pela convergência dos sentidos expostos a fim de explicitar a estrutura do que, na pesquisa, se interroga.

Os momentos (1), (2) e (3), constituintes da análise dos dados, foram feitos de modo separado. Ou seja, seguimos esses procedimentos para cada uma das comunidades consideradas: Facebook e Orkut. Esse momento da análise na pesquisa é denominado análise ideográfica. Nele o pesquisador visa às unidades de significado individuais, isto é, visa ao que se revela em cada postagem de um sujeito específico e que é relevante para compreender o que interroga. Quando nos voltamos para o que na análise ideográfica se mostra, interrogamos isso que se mostra e, portanto, adentramos ao movimento interpretativo que visa à generalidade. Agora não mais precisamos (e não queremos) separar os grupos - Facebook e Orkut, pois nos interessa o que é dito sobre Matemática pelos sujeitos, ou melhor, interessanos o modo como eles dizem o que compreendem de Matemática. Isso, que no geral vai se mostrando na análise interpretativa, é nomeado categoria aberta. 
Em nossa pesquisa as categorias abertas são quatro: Expressão pela Fala, Expressão por meio de uma Imagem, Expressão pela Linguagem Matemática e o Ouvir o outro.

Para este texto não temos a pretensão de trazer a discussão de todas as categorias. Elegemos uma delas - a Expressão pela Fala - a título de exemplificação do feito. Começamos mostrando a estrutura inicial do movimento de análise, em que são construídos quadros com as unidades de significado das falas dos sujeitos. Vale esclarecer que, para a organização desses quadros, utilizamos códigos que indicam: a postagem dos sujeitos $(\mathrm{P})$, a resposta dada a uma determinada postagem por outro sujeito $(\mathrm{R})$ e a identificação do sujeito que entra no diálogo na ordem em que aparecem (m). Assim, se tomamos, por exemplo, o código P1.m1 ele indica uma primeira postagem (P1) do primeiro sujeito (m1). Já o código R4-P1.m3 indica uma quarta resposta $(\mathrm{R} 4)$ dada à primeira postagem (P1) pelo terceiro sujeito (m3).

Quadro 1: Análise Ideográfica

\begin{tabular}{|c|c|}
\hline Postagem e Respostas/Unidades de significado & Asserção Articulada \\
\hline $\begin{array}{l}\text { P1.m1: problema envolvendo logaritmos e progressão } \\
\text { aritmética. alguém me ajuda? pvff } \\
\mathrm{S}=\log _{4}{ }^{2}+\log _{4} 2^{3}+\log _{4} 2^{5}+\log _{4} 2^{7}+\cdots+\log _{4} 2^{199}\end{array}$ & $\begin{array}{l}\text { O sujeito pede ajuda para a resolução de um } \\
\text { exercício que envolve logaritmos e } \\
\text { progressão aritmética. Apresenta o exercício } \\
\text { por meio de uma imagem (scaner). }\end{array}$ \\
\hline R1-P1.m2: ajuda em que? Kkkkk & $\begin{array}{l}\text { Como o sujeito } m 1 \text { não explicitou em que ele } \\
\text { precisava de ajuda no exercício, o membro } \\
\text { da comunidade } m 2 \text { pergunta em que } m 1 \\
\text { precisa de ajuda. }\end{array}$ \\
\hline R2-P1.m1: soma dos termos & $\begin{array}{l}m 1 \text { responde que precisa de ajuda para } \\
\text { determinar a soma dos termos. }\end{array}$ \\
\hline $\begin{array}{l}\text { R3-P1.m3: Tem uma propriedade que mata essa questão. Log na } \\
\text { base ân é igual a }(1 / \mathrm{n}) \log \text { de a. }\end{array}$ & $\begin{array}{l}m 3 \text { responde a } m 1 \text { dizendo que existe uma } \\
\text { propriedade que pode auxiliar na resolução } \\
\text { do exercício e a escreve usando palavras e } \\
\text { símbolos. }\end{array}$ \\
\hline $\begin{array}{l}\text { R4-P1.m3: Não sei se tu vai entender a propriedade com o que } \\
\text { eu digitei. }\end{array}$ & $\begin{array}{l}m 3 \text { se preocupa em não ser entendido devido } \\
\text { a forma que utiliza para descrever a } \\
\text { propriedade. }\end{array}$ \\
\hline R5-P1.m2: $\mathrm{S}=\log 2^{\wedge} 10000$ base 4 & $\begin{array}{l}m 2 \text { utiliza a fórmula que } m 3 \text { sugere, já } \\
\text { substituindo as 'letras' por 'números'. }\end{array}$ \\
\hline $\begin{array}{l}\text { R6-P1.m4: } \\
\mathrm{S}=1 / 2 .(1+3+5+7+\ldots+199)=1 / 2 .((1+199) .100 / 2=20.000 / 4=5.000\end{array}$ & $\begin{array}{l}m 4 \text { resolve o exercício utilizando a fórmula } \\
\text { de soma dos termos dada por } m 3 \text { para } \\
\text { auxiliar } m 1 \text {. }\end{array}$ \\
\hline R7-P1.m1: vlw, vou tentar fazer aqui & $\begin{array}{l}m 1 \text { agradece as dicas e diz que irá tentar } \\
\text { resolver. }\end{array}$ \\
\hline R8-P1.m2: pq 1/2? & $\begin{array}{l}m 2 \text { retoma o diálogo e indaga } m 4 \text { com o } \\
\text { objetivo de entender porque ele utiliza o } \\
\text { valor } 1 / 2 \text {. }\end{array}$ \\
\hline $\begin{array}{l}\text { R9-P1.m4: todos os } \log 42=1 / 2, \log 42^{\wedge} 3=3 / 2 \ldots \text { vc coloca o } 1 / 2 \\
\text { em evidência e vai ficar uma p.a de razão } 2(1,3,5,7, \ldots, 199) \text { aqui } \\
\text { tem cem termos. } S=1 / 2[(1+199) .100 / 2]\end{array}$ & $\begin{array}{l}m 4 \text { responde a pergunta feita por } m 2 \text {, } \\
\text { explicando porque utilizou } 1 / 2 \text {. }\end{array}$ \\
\hline R10-P1.m2: ah entendi... vlw & $\begin{array}{l}m 2 \text { diz ter entendido a explicação e } \\
\text { agradece. }\end{array}$ \\
\hline $\begin{array}{l}\text { R11-P1.m5: Primeiro termo: } \log 2=\mathrm{a} \ldots . .44^{\wedge} \mathrm{x}=2\left(2^{\wedge} 2\right)^{\wedge} \mathrm{x}=2 \\
2^{\wedge} 2 \mathrm{x}=22 \mathrm{x}=1 \mathrm{x}=1 / 2 \text { Temos que achar o segundo termo para } \\
\text { encontrar a razão: } \log 2^{\wedge} 3=\mathrm{b} \ldots . .44^{\wedge} \mathrm{b}=2^{\wedge} 3\left(2^{\wedge} 2\right)^{\wedge} \mathrm{b}=2^{\wedge} 32^{\wedge} 2 \mathrm{~b}\end{array}$ & $\begin{array}{l}m 5 \text { apresenta uma resolução detalhada do } \\
\text { exercício expressando-se por meio da } \\
\text { linguagem matemática. }\end{array}$ \\
\hline
\end{tabular}




\begin{tabular}{|l|l|}
\hline \multicolumn{1}{|c|}{ Postagem e Respostas/Unidades de significado } & \multicolumn{1}{c|}{ Asserção Articulada } \\
\hline$=2^{\wedge} 32 \mathrm{~b}=3 \mathrm{~b}=3 / 2$ Razão: $3 / 2-1 / 2=1$ Último termo: $\log 2^{\wedge} 199$ & \\
$=\mathrm{c} \ldots .44^{\wedge} \mathrm{y}=2^{\wedge} 199\left(2^{\wedge} 2\right)^{\wedge} \mathrm{y}=2^{\wedge} 1992^{\wedge} 2 \mathrm{y}=2^{\wedge} 1992 \mathrm{y}=199$ & \\
$\mathrm{y}=199 / 2$ Achando o número de termos: an $=\mathrm{a} 1+(\mathrm{n}-1) \cdot \mathrm{r}$ an $=199 / 2$ & \\
$\mathrm{n}=? \mathrm{r}=11 / 2+(\mathrm{n}-1) .1=199 / 21+2 \mathrm{n}-2=1992 \mathrm{n}=200 \mathrm{n}=100$ Soma & \\
dos termos pela fórmula: $\mathrm{S}=(\mathrm{an}+\mathrm{a} 1) / 2 . \mathrm{n} \mathrm{S}=(1 / 2+199 / 2) / 2$. & \\
$100 \mathrm{~S}=(200 / 2) / 2.100 \mathrm{~S}=100 / 2.100 \mathrm{~S}=5000$ & \\
\hline $\boldsymbol{R} 12-\boldsymbol{P 1 . m 6}$ O O produto se torna uma soma em logaritmos. Basta & m6 justifica a resolução de $m 5$ falando da \\
voltar pro produto e fazer a p.a dos expoentes. & propriedade do produto de logaritmos. \\
\hline
\end{tabular}

Fonte: Elaborado pelas autoras

Interrogando os modos pelos quais os sujeitos se expressam acerca do conteúdo matemático no ciberespaço, voltamo-nos para o quadro de análise ideográfica, que traz as postagens dos sujeitos (unidades de significado) e as asserções articuladas, buscando convergências desses modos de expressão. Esse movimento levou-nos a construção de novos quadros que expressam as convergências percebidas. Tais convergências expõem ideias nucleares que possibilitam ao pesquisador dizer do que é compreendido acerca do expresso pelos sujeitos, à luz da sua interrogação. A seguir trazemos um exemplo do quadro de convergência.

Quadro 2: convergência de unidades de significado

\begin{tabular}{|l|c|}
\hline \multicolumn{1}{|c|}{ Convergências } & Códigos \\
\hline 1. Pede ajuda expressando-se por meio da fala & P1m1 \\
\hline 2. Expõe uma dúvida usando uma imagem. & P1m1 \\
\hline 3. Busca compreensão fazendo um apelo ao outro por meio da fala. & R1P1m2 \\
\hline 4. Esclarece, expõe dúvidas ou agradece por meio da fala. & R2P1m1; R7P1m1; R10P1m2 \\
\hline 5. Expõe um modo de fazer usando a fala e a linguagem matemática. & R3P1m3, R9P1m4 \\
\hline 6. Expõe, por meio da fala, uma preocupação. & R5P1m2; R6P1m4; R9P1m4; \\
\hline 7. Expressa, por meio da linguagem matemática, um modo de fazer. & R11P1m5 \\
\hline 8. Expõe uma dúvida por meio da fala. & R8P1m2 \\
\hline 9. Expõe, por meio da fala, uma justificativa para o feito. & R12P1m6 \\
\hline
\end{tabular}

Fonte: Elaborado pelas autoras

Vale destacar que, neste quadro 2, mostramos as convergências de unidades de significados expressas por ideias nucleares apenas da postagem 1. Na pesquisa tivemos trinta e oito convergências relevantes para entender como o diálogo acerca do conteúdo matemático se dá em grupos das redes sociais Facebook e Orkut. As ideias nucleares levam-nos, novamente, a interrogar o que é expresso nos discursos dos sujeitos. Esse interrogar permitenos articular compreensões e ver generalidades que, expressas pelas categorias abertas, revelam o sentido dos modos de expressão dos sujeitos. 
A Expressão pela Fala, uma das categorias de análise da pesquisa, é um modo do diálogo, acerca dos conteúdos matemáticos, ser possível no ciberespaço. Mas o que isso significa? Segundo o dicionário online, Infopédia, a fala é o ato ou efeito de falar. Falar, por sua vez, significa dizer, exprimir por palavras ou ainda, discursar. Mas como, então, dizer de 'fala' no ciberespaço? - mais especificamente nesse ambiente em que a comunicação é escrita. Interpretamos que a expressão pela fala se mostra como um dos modos de os sujeitos utilizarem, na maioria das vezes, a Língua Materna na forma escrita, para dialogar, para conversarem acerca de conteúdos matemáticos. Machado (2001) diz que o uso da Língua Materna se dá porque, para falarmos de Matemática é preciso, também, recorrer à oralidade. Justifica o autor: a escrita matemática não comporta a oralidade e, por isso, empresta da Língua Materna tal característica. Por que ela empresta? Para se fazer entender. Ou seja, para que seja possível, ao sujeito, explicitar os procedimentos por ele adotados na resolução de um problema, o modo pelo qual um raciocínio é empregado, as dúvidas que surgem, dentre outras possibilidades.

Ao analisarmos os modos pelos quais os sujeitos da pesquisa se comunicam acerca de conteúdos matemáticos, vimos a expressão pela fala. Isto é, embora a 'oralidade' no ciberespaço se constitua de forma escrita, pode-se ver o modo discursivo usado para se dizer algo. A expressão pela fala é, pois, um modo de permitir que o pensamento se realize (Merleau-Ponty, 2002). Silva (1994, p. 57), ao considerar essa afirmação de Merleau-Ponty, diz que "o pensamento existe pela fala, e somente nesta atitude de expressão é que se realiza a significação". Vemos que a fala, para esses autores, é um forte componente expressivo que visa tanto expor o sentido do compreendido quanto permitir a compreensão. A fala veicula a significação. É pela fala que o outro tem 'acesso' ao meu pensar e é também por ela que temos 'acesso' ao pensar do outro. Na pesquisa, nos modos de expressão dos sujeitos, vimos que a expressão pela fala é utilizada com diversos objetivos, variando, desde uma solicitação de ajuda (P1.m1) ou opiniões (R4-P1.m3), até àquelas que procuram mostrar o movimento do pensar, expondo raciocínios utilizados (R12-P1.m6). A expressão pela fala é um modo de expressão dos sujeitos da pesquisa, que nos remete a esse movimento que na palavra, ou na oralidade (que no ciberespaço se mostra pela escrita), busca expor o pensamento que o sujeito compartilha com o outro, se abrindo ao diálogo. Nesse sentido de diálogo, o dizer enlaça o ouvir. Ou melhor, no diálogo os sujeitos vão se fazendo atentos à fala e buscando modos de compartilhar informações, tentando expor ao outro o compreendido na tentativa de se fazer entender. $\mathrm{O}$ outro, atento, ouvinte, compartilha esse pensar. Entra no diálogo, se abre à conversa, opina, expõe compreensões. O diálogo é, portanto, um movimento que exige, para 
além da fala, o ouvir. Não basta falar de Matemática; é preciso ouvir o dizer do outro, buscando compreendê-lo. Consideramos que, no ciberespaço, a expressão pela fala, quando se conversa de Matemática, é um modo expressivo que procura fazer o pensamento deslanchar e busca trazer o outro para compartilhar o percebido, compreendido e interpretado, de tal modo que o diálogo se torne possível. Assim, no ciberespaço, a expressão pela fala é um modo discursivo em que os sujeitos se põem a conversar acerca de Matemática.

\section{Abrindo as janelas para o compreendido}

Desenvolvendo uma pesquisa de abordagem fenomenológica, durante o percurso fomos orientados pela pergunta 'como o diálogo acerca do conteúdo matemático é possível e se dá em comunidades/grupo das redes sociais: Facebook e Orkut?'. Para este texto trouxemos um recorte do compreendido. Vale destacar que esse compreendido foi possível em certo contexto: da experiência vivida com a fenomenologia e com os sujeitos dos grupos pesquisados. A intenção de expor compreensões acerca da comunicação e do diálogo no ciberespaço, nos fez entender que a comunicação se dá pela existência de uma significação comum, que permite que as pessoas se relacionem, se expressem, sejam compreendidas e se façam compreender. Entende-se que o diálogo independe do espaço em que ocorre, uma vez que mantém suas características gerais sem as quais deixaria de ser o que é. Para nós, fez sentido entender a comunicação no ciberespaço sem que se pretendesse associá-la (ou compará-la) àquela que acontece em situações presenciais. Buscamos explicitar o que compreendemos acerca do diálogo no ciberespaço e, para tanto, recorremos a autores como Bicudo (2011) e Ales Bello (2006), que nos mostram que o que mantém os sujeitos em diálogo é uma relação empática. Ou seja, o que permite que o diálogo se dê é a percepção de que há o outro como semelhante a mim, aberto ao ouvir e ao dizer, atento as minhas dúvidas, disposto a conversar. No ciberespaço a empatia se apresenta como ato de entrar em sintonia com a expressão do outro ou, conforme diz Bicudo (2011), tornando-se presença pela fala.

A interpretação das outras três categorias da pesquisa, que não trouxemos neste texto, dizem dos modos como o diálogo acontece: o ouvir o outro, a expressão por meio da linguagem matemática e a expressão por meio de imagem. Cada uma delas diz da forma que os sujeitos encontram para dialogar, para compartilhar informações, produzir conhecimento. Compreendemos que o solo do diálogo, isto é, o que o torna possível, é o ouvir. O ouvir permite o diálogo e este se dá de diferentes modos, porém numa mesma direção: a da intenção 
de se fazer entender. Esses modos pelos quais os sujeitos se abrem ao diálogo vão constituindo, no ciberespaço, um ‘espaço comunicativo' onde é possível falar de Matemática.

\section{Referências}

ALES BELLO, A. Introdução à Fenomenologia. Trad. Ir. Jacinta Turolo Garcia e Miguel Mahfoud. Bauru: Edusc, 2006.

BICUDO, M. A. V. (Org.). Pesquisa Qualitativa Segundo a Visão Fenomenológica. 1 ed. São Paulo: Cortês, 2011.

BICUDO, M. A. V.; ROSA, M.. Realidade e Cibermundo - horizontes filosóficos e educacionais antevisto. Canoas, Ed. ULBRA, 2010.

COELHO JUNIOR, N. E.. Consciência, Intencionalidade e Intercorporeidade. Paidéia. Ribeirão Preto/SP. 2002, v. 12, n. 22, p. 97-101.

FALA. In: Infopédia. Porto: Porto Editora, 2003-2016. Disponível em: $<$ http://www.infopedia.pt/dicionarios/lingua-portuguesa/fala>. Acesso em: 20 abr. 2016.

FINI, M. I. Sobre a Pesquisa Qualitativa em Educação que tem a Fenomenologia como Suporte. In: BICUDO, M. A. V.; ESPÓSITO, V. H. C. (Orgs). A pesquisa qualitativa em educação: um enfoque fenomenológico. Piracicaba: Editora UNIMEP, 1994, p. 23-33.

FRAGATA, J. A fenomenologia de Husserl como fundamento da filosofia. Braga: Livraria Cruz, 1959.

HUSSERL, E. A crise da humanidade europeia e a filosofia. Porto Alegre; EDIPUCRS, 2008.

LÉVY, P. Cibercultura. Trad. Carlos Irieneu da Costa. São Paulo: Editora 34, 1999.

MACHADO, N. J. Matemática e Língua Materna: Análise de uma impregnação mútua. São Paulo: Cortez, 2001.

MERLEAU-PONTY, M. Fenomenologia da Percepção. São Paulo: Martin Fonte, 1994.

MERLEAU-PONTY, M. A prosa do mundo. São Paulo: Cosac \& Naify, 2002.

SILVA, U. R. da. A Linguagem Muda e o Pensamento Falante: sobre a fenomenologia da linguagem em Merleau-Ponty. Porto Alegre: EDIPUCRS, 1994.

SILVA, P. C. G. Da. A fenomenologia de Husserl: uma breve leitura. Brasil Escola, filosofia, s/d. Disponível em $<$ http://meuartigo.brasilescola.com/filosofia/a-fenomenologia-husserl-uma-breveleitura.htm.>. Acesso em: 23 de abr. 2016. 